\title{
EI RECURSO HUMANO COMO FACTOR DETERMINANTE EN LA INNOVACIÓN DE LAS EMPRESAS BOLIVIANAS
}

\section{Vivian María Verduguez Vargas}

\section{RESUMEN}

Este estudio analiza el grado de impacto de la presencia de recurso humano calificado en los resultados de innovación de procesos, productos y en la productividad de las empresas bolivianas. Tomando como base el modelo de Crepon, Duguet, y Mairesse (CDM) desarrollado en 1998 y la primera encuesta de innovación realizada en Bolivia a empresas privadas, se logra establecer que existe una relación positiva entre la presencia de recurso humano calificado, los resultados de innovación y la productividad laboral de las empresas estudiadas. En relación con las características del recurso humano, los resultados muestran que la presencia de recurso humano calificado en una empresa tiene un impacto positivo sobre los resultados de la innovación y sobre la productividad laboral. Por otra parte, se establece que la presencia de recurso humano no calificado provoca un efecto inverso sobre la productividad laboral. En cuanto a las características de las empresas, se logra establecer que la presencia de capital extranjero y la realización de exportaciones afectan positivamente las inversiones en innovación. Finalmente, se resalta la importancia de conocer cuáles son los esfuerzos de innovación que hacen las empresas y los impactos de estos en la productividad a fin de mejorar la toma de decisiones sobre inversiones del sector público y privado.

Palabras Clave: Bolivia, Inversión en Innovación, Innovación, Recurso Humano, Productividad Laboral, CDM.

DOI: 10.23881/idupbo.020.2-8e 